\title{
Overexpression of Insulin Receptor Substrate 1 (IRS1)
}

\section{Promotes Radioresistance In A172 Glioblastoma Cell}

Line

\author{
Gökhan Görgişen $^{1^{\star}}$, Tahir Çakır $^{2}$, Can Ateş $^{3}$, İsmail Musab Gülaçar ${ }^{1}$, Zafer Yaren $^{1}$ \\ ${ }^{1} V$ an Yuzuncu Yil University, Faculty of Medicine, Department of Medical Biology, Van, Turkey \\ ${ }^{2} V$ an Yuzuncu Yil University, Faculty of Medicine, Department of Biophysics, Van, Turkey \\ ${ }^{3} V$ an Yuzuncu Yil University, Faculty of Medicine, Department of Biostatistics, Van, Turkey
}

\begin{abstract}
Insulin receptor substrate 1 (IRS1) is the main adaptor molecule in insulin and insulin like growth factor signaling. Increased level of expression of IRS1 and IGF-1R proteins are associated with many human malignancies. They also induced resistance to therapeutic approaches such as chemo- and radiotherapy in cancer treatment however their molecular mechanisms are still unclear. Glioblastoma Multiforme (GBM) is the most common primary brain tumor in adults and radiotherapy has a pivotal role in its treatment. In this study, it is aimed to determine the relationship between IRS1 expression and radiosensitivity of GBM cells. Therefore, A172 cells transfected with pcDNA3.1-HA-tagged human IRS1 gene. Its overexpression was confirmed by western blot. IRS1 overexpressed A172 cells were irradiated with 5,8 and 10 Gray ionizing radiation and their effects on cell viability determined by MTT and clonogenic assay. Our results showed that overexpression of IRS1 led a decrease on sensitivity of the radiation in GBM cells. As a conclusion, this study should be confirmed by further molecular analysis and in vivo studies. IRS1 may be a predictive marker of radiosensitivity for GBM
\end{abstract}

Key Words: IRS1, IGF-1R, insulin signaling, GBM, radioresistance

\section{Introduction}

Insulin like growth factor (IGF) signaling has crucial roles in the progress of cancer (1-3). Its overexpression is associated with proliferation, metastasis, chemo and radioresistance in many cancer types such as ovarian, breast and colorectal (4-6).

IGF binds and activates to insulin like growth factor receptor (IGF-1R). IGF-1R activation triggers the signaling pathways that mediates proliferation, cell survival and metastasis (7). Insulin receptor substrate 1 (IRS1) is the main adaptor molecule that interacts with IGF-1R after ligand binding. IGF-1R phosphorylates tyrosine residues of IRS1 that leads to activation of IRS1 proteins. Activated IRS1 induces the activation of AKT and MAPK proteins that regulates metabolic and proliferative functions of the cells $(8,9)$. Therefore, IRS1 overexpression is an important factor in tumorigenesis.

Although, functions of IGFR pathway have been well-explored in cancer during recent years (7), its effects on radiotherapy remain unclear. Radiotherapy is one of the main therapeutic approach used in cancer treatment $(10,11)$. Ionizing radiation induces different cell death mechanisms through different damages in DNA. These damages could be oxidizing of DNA bases, single strand and double strand breaks and activation of different signaling pathways including IGF-1R $(12,13)$. IGF-1R overexpression is known to inhibit radiation-induced cell death in mouse embryo fibroblast whereas its downregulation was shown to increase apoptosis (14). In addition to IGF-1R overexpression, elevation of IRS1 expression also induced radioresistance in estrogen receptor-positive breast cancer cell line (15). Overexpression IRS1 induced resistance to activation-cell death in T-Cell Hybridoma (16). Clinical results confirmed these in vitro studies too. Many clinical studies showed that IGF-1R overexpression is correlated with disease recurrence after radiotherapy in breast cancer and cervical cancer patients (17,18). Glioblastoma multiforme (GBM) 
Table 1. Statistical analysis between control, mock transfected and IRS1 transfected groups and their multiple comparisons

\begin{tabular}{lccccc}
\hline \multirow{2}{*}{ Groups } & Factor & \multirow{2}{*}{ Mean } & St. Error & \multicolumn{2}{c}{$95 \%$ Confidence Intervals } \\
\cline { 5 - 6 } Control & $24 \mathrm{~h}$ & 104,359 & 1,653 & 100,922 & 107,796 \\
& $48 \mathrm{~h}$ & 103,072 & 1,179 & 100,620 & 105,524 \\
& $72 \mathrm{~h}$ & 110,397 & 2,573 & 105,047 & 115,748 \\
\multirow{3}{*}{ Mock } & $24 \mathrm{~h}$ & 104,315 & 1,653 & 100,878 & 107,752 \\
& $48 \mathrm{~h}$ & 99,779 & 1,179 & 97,327 & 102,230 \\
& $72 \mathrm{~h}$ & 108,577 & 2,573 & 103,226 & 113,927 \\
\multirow{2}{*}{ pcDNAIRS1 } & $24 \mathrm{~h}$ & 127,478 & 1,169 & 125,048 & 129,908 \\
& $48 \mathrm{~h}$ & 125,243 &, 834 & 123,510 & 126,977 \\
& $72 \mathrm{~h}$ & 129,226 & 1,819 & 125,443 & 133,010 \\
\hline
\end{tabular}

\begin{tabular}{cccc}
\hline & & Multiple Comparisons & \\
\hline F1 & (I) Group & J) Group & p \\
& Control & Mock &, 985 \\
& & pcDNA-IRS1 &, 001 \\
& Mock & Control &, 985 \\
& & pcDNA-IRS1 &, 001 \\
& pcDNA-IRS1 & Control &, 001 \\
& & Mock &, 001 \\
& Control & Mock &, 062 \\
& & pcDNA-IRS1 &, 001 \\
& Mock & Control &, 062 \\
& \multirow{2}{*}{ pcDNA-IRS1 } & pcDNA-IRS1 &, 001 \\
& & Control &, 001 \\
& Control & Mock &, 001 \\
& & Mock &, 622 \\
& Mock & pcDNA-IRS1 &, 001 \\
& & Control &, 622 \\
& pcDNA-IRS1 & pcDNA-IRS1 &, 001 \\
& & Control &, 001 \\
& & Mock &, 001 \\
\hline
\end{tabular}

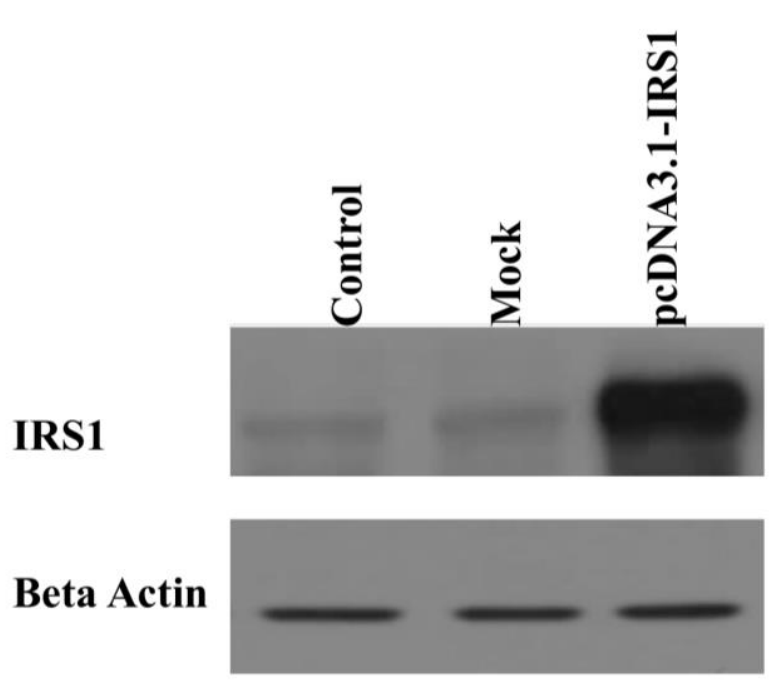

Fig. 1. Overexpression of IRS1 in A172 cells is one of the most frequent and aggressive type of intracranial tumors and radiotherapy is commonly used as a therapeutic approaches in treatment (19). Osuka et al. showed that overexpression of IGF$1 \mathrm{R}$ led an increase radioresistance of GBM (20). Although there are many studies that showed the association between expression of IGF- $1 \mathrm{R}$ and response to radiotherapy, there is not enough information about its molecular mechanisms. In this study, it is aimed to determine the effects of IRS1 overexpression on radiosentivity of GBM cell line.

\section{Material and Methods}

Reagents and Cell Culture: IRS1 and Beta Actin antibodies were obtained from Santa Cruz 
a.

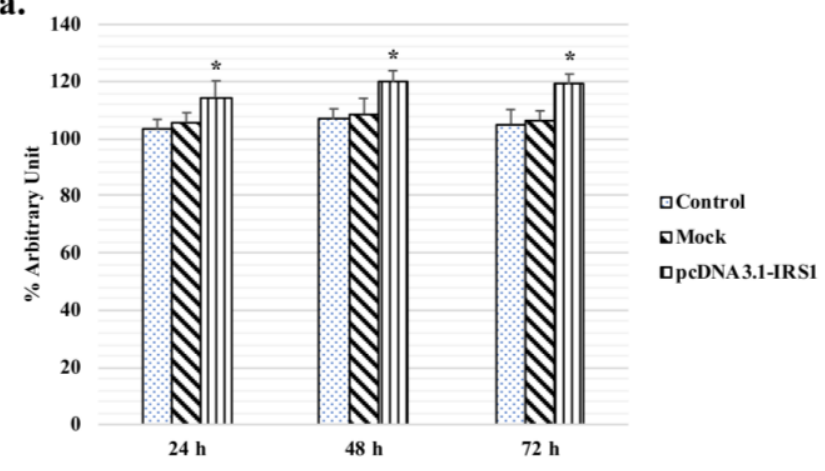

b.

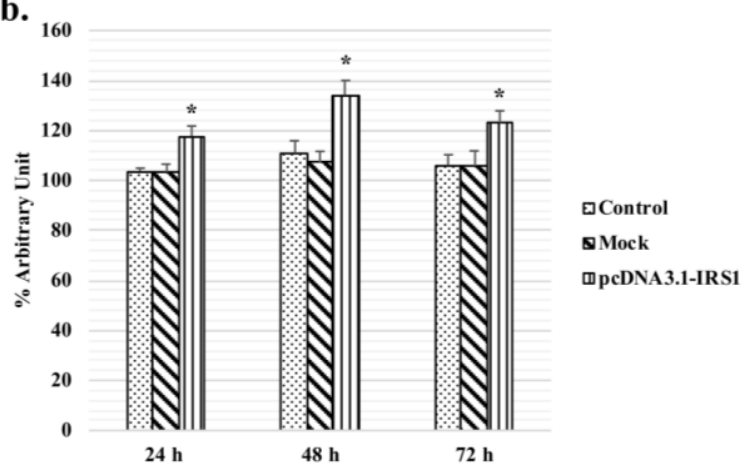

c.

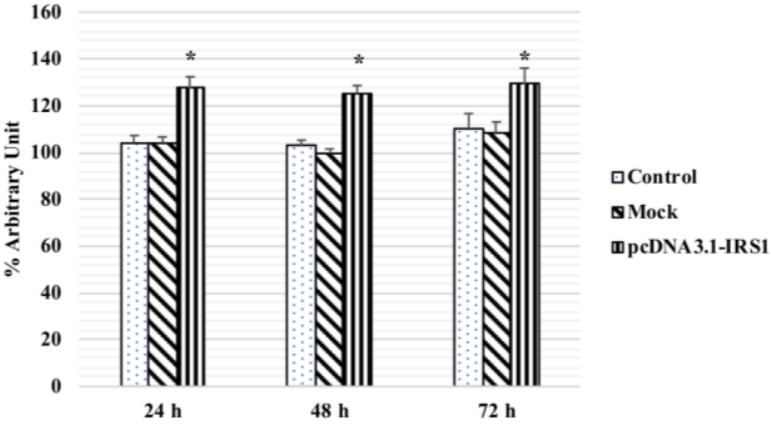

Figure 2. Cell viability levels of A172 and IRS1 overexpressed A172 cells after treatment of 5Gr (a), 8 Gr (b), 10 Gr $(\mathbf{c})$ radiation $(* p<0.001)$

Biotechnology Inc. (Santa Cruz, CA). Anti-rabbit HRP and anti-mouse HRP were purchased from BioRad (Hercules, CA). A172 cells, human glioblastoma cell line, cultured in Dulbecco's Modified Eagle's Medium supplemented with 50 $\mathrm{mg} / \mathrm{ml}$ streptomycin, $100 \mathrm{mg} / \mathrm{ml}$ penicillin, and 1 mM L-glutamine.

Transfection: A172 cells were transfected with 10 ug HA-tagged pcDNA3.1 human IRS1 expression vector by TurboFect transfection reagent (ThermoFisher Scientific, US) according to manufacturer instructions.

Cell Viability Test: MTT: IRS1 overexpressed, mock transfected and control A172 cells were plated at 5000 cells/well in 96 well plates with 6 replicates. After overnight incubation, cells were treated with 5, 8 and 10 Gray radiations then

incubated at $37{ }^{\circ} \mathrm{C}, 5 \% \mathrm{CO}_{2}$ for 24,48 and 72 hours. At the end of incubation, $5 \mathrm{mg} / \mathrm{ml} \mathrm{MTT}$ solution was added to each well for 4 hours at $37^{\circ} \mathrm{C}$ in an incubator, then medium was removed and formazan crystals dissolved in DMSO $(100 \mu \mathrm{L})$. The amount of MTT formazan products formed was determined by measuring absorbance (A) at $540 \mathrm{~nm}$, with $690 \mathrm{~nm}$ as the reference wavelength.

Western Blotting: Control and transfected cells were lysed in Triton X-100 buffer containing 50
mM HEPES, pH 7.0, $150 \quad \mathrm{mM} \quad \mathrm{NaCl}, \quad 10 \%$ glycerol, $1.2 \%$ Triton X-100, $1.5 \mathrm{mM} \mathrm{MgCl} 2,1$ mM EGTA, $10 \mathrm{mM}$ sodium pyrophosphate, 100 $\mathrm{mM} \mathrm{NaF}, 1 \mathrm{mM}$ sodium orthovanadate, $1 \mathrm{mM}$ PMSF, 0.15 units $/ \mathrm{ml}$ aprotinin, $10 \mu \mathrm{g} / \mathrm{ml}$ leupeptin, and $10 \mu \mathrm{g} / \mathrm{ml}$ pepstatin A. For western blot analysis 75 microgram proteins were fractionated by SDS-PAGE, then transferred to PVDF membranes. The membranes were blocked in 5\% skim milk powder in PBST. The blots were labeled with IRS1 antibody. Actin was used as loading control for these blots. Signal intensity on blots were determined using the enhanced chemiluminescent detection system.

Colony Forming Assay: IRS1 overexpressed, mock transfected and control A172 cells were plated at 2000 cells/well with double replicates in six well plates. After overnight incubation, one of the six well plate was treated with $8 \mathrm{Gr}$ radiations and the other one was used as a control/untreated group, and incubated for 9 days. After incubation, cells were fixed by methanol-asetic acid solution and stained with $5 \mathrm{~mL} 0.01 \%(\mathrm{w} / \mathrm{v})$ crystal violet in methanol for $15 \mathrm{~min}$. Colonies were counted with Image J software programme.

Statistical Analysis: All data were presented as the mean \pm SEM from three independent experiments for MTT analyses. Each MTT analyses were performed with six replicates. 


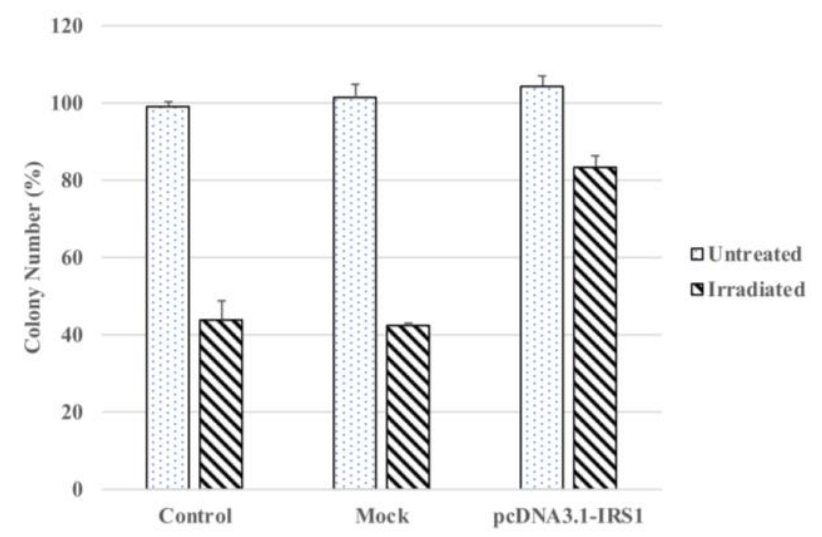

Fig. 3. Clonogenic assay were performed on control A172 cells and transfected IRS1 A172 cells after 8 Gray irradiation

Two-way analysis (ANOVA) was used for multiple comparison in data analyses. IBM SPSS Statistics package version 23.0 was used to evaluate the data of the study.

\section{Results}

Ectopic expression of IRS1 was confirmed by western blot analysis and IRS1 transfected A172 cells were found to have higher level of IRS1 expression compared to mock transfected and control group (Figure 1).

We wanted to determine the effects IRS1 overexpression on radiation. Therefore, we treated A172 cells at 5, 8 and 10 Gray radiation and incubated for 24,48 and 72 hours. Results showed that overexpression of IRS1 led an increase radioresistance of glioblastoma cells significantly compared to control cells in all incubation groups (Figure 2, Table 1) $(\mathrm{p}<0.05)$. Effects of radiation induced the cell death after $72 \mathrm{~h}$ and 8 gray radiation dose was observed as an effective dose for glioblastoma cell lines. It was also shown that, radiation treatment had its apoptotic activity after 72 hours in IRS1 overexpression groups. Significant changes in cell death between IRS1 overexpression groups that were incubated for different time lenghts were not observed (Table 1) ( $p>0.05$ ).

The differences in viability of all groups were assessed by clonogenic assay. Therefore, the cells were treated at 8 Gray as an optimum dose and incubated for 9 days. Clonogenic assay results showed that 8 Gray radiation led a decrease level on the survival of all cells compared to their untreated groups, however IRS1 overexpression group was found to more resistant to radiotherapy compare to the other groups (Figure 3). In control and mock transfected groups, colony numbers decreased $60 \%$ after 8 Gray radiation treatment whereas we only $20 \%$ decreased was observed in colony numbers in IRS1 overexpressing group after the same treatment.

\section{Discussion}

Increased expression levels of IGF-1R and IRS1 are associated with many human malignancies which implies that both of the proteins have a pivotal role in carcinogenesis $(9,21,22)$. Recent studies have also shown that IGF-1R and IRS1 are responsible for the development of chemo- and radioresistance in cancer cells but their molecular mechanisms have not been discovered yet (23). Radiotherapy has a crucial role in glioblastoma treatment. However, resistance to radiation is a major concern on the treatment of GBM (24). Therefore, clarifying the molecular pathways is so important to develop new therapeutic options in GBM.

This is the first report that shows the correlation between IRS1 overexpression and radioresistance in GBM cell line. Our results showed IRS1 overexpression significantly induced radioresistance in GBM cell line. Ionizing radiation produces DNA damage either by singlestrand and double-strand DNA breaks (DSB). Radiotherapy induced DNA damage activates several pathways including DNA damage response to protect the cells against genomic instability (11, 23). During DNA repairing pathway, IRS1 can interact with RAD51 protein that is responsible for DSB repairing system (25). In this study, it is possible that overexpression of IRS1 may lead an increase on the interaction with RAD51 and induce DNA repairing system. This molecular mechanism could be one of the main reason of resistance in $\mathrm{A} 172$ cells.

AKT, MAPK, PI3K and mTOR are the main downstream targets of IRS1 protein (26). All these proteins promote DNA repair systems through different signaling pathways such as XRCC1, BRCA1, FANCD2 (27-30). Increasing the level of IRS1 in A172 cells may trigger DNA damage response system via activation of AKT, mTOR and MAPK pathways and these activations may result in radioresistance. 
GLUT1 is widely expressed glucose transporter in human tissues (31). GLUT1 overexpression is associated with radioresistance in different cancer types $(32,33)$. Its expression is induced by many oncogenes such as MAPK and AKT during carcinogenesis and hypoxia (31). During insulin signaling, glucose uptake rates of the cells is regulated by IRS1 proteins through the activation of AKT and translocation of GLUT proteins to the cell membrane (9). GLUT1 expression could be elevated by increased IRS1 expression in A172 cells and this overexpression may cause to reduce the sensitivity to radiotherapy.

As a summary, overexpression of IRS1 promotes resistance to radiotherapy in GBM cells via different molecular mechanisms. All these mechanisms should be confirmed by further molecular analysis and in vivo studies.

\section{References}

1. Coppola D, Ferber A, Miura M, et al. A functional insulin-like growth factor I receptor is required for the mitogenic and transforming activities of the epidermal growth factor receptor. Mol Cell Biol 1994; 14: 4588-4595.

2. Guevara-Aguirre J, Guevara A, Palacios I, Perez M, Procel P, Teran E. GH and GHR signaling in human disease. Growth Horm IGF Res 2018; 38: 34-38.

3. Valentinis B, Morrione A, Taylor SJ, Baserga R. Insulin-like growth factor I receptor signaling in transformation by src oncogenes. Mol Cell Biol 1997; 17: 3744-3754.

4. An Y, Cai Y, Guan Y, et al. Inhibitory effect of small interfering RNA targeting insulin-like growth factor-I receptor in ovarian cancer OVCAR3 cells. Cancer Biother Radiopharm 2010; 25: 545-552.

5. Christopoulos PF, Corthay A, Koutsilieris M. Aiming for the Insulin-like Growth Factor-1 system in breast cancer therapeutics. Cancer Treat Rev 2018; 63: 79-95.

6. Kaulfuss S, Burfeind P, Gaedcke J, Scharf JG. Dual silencing of insulin-like growth factor-I receptor and epidermal growth factor receptor in colorectal cancer cells is associated with decreased proliferation and enhanced apoptosis. Mol Cancer Ther 2009; 8: 821-833.

7. Simpson A, Petnga W, Macaulay VM, WeyerCzernilofsky U, Bogenrieder T. Insulin-Like Growth Factor (IGF) Pathway Targeting in Cancer: Role of the IGF Axis and Opportunities for Future Combination Studies. Target Oncol 2017; 12: 571-597.

8. Amutha P, Rajkumar T. Role of Insulin-like Growth Factor, Insulin-like Growth Factor
Receptors, and Insulin-like Growth Factorbinding Proteins in Ovarian Cancer. Indian J Med Paediatr Oncol 2017; 38: 198-206.

9. Gorgisen G, Gulacar IM, Ozes ON. The role of insulin receptor substrate (IRS) proteins in oncogenic transformation. Cell Mol Biol (Noisyle-grand) 2017; 63: 1-5.

10. Jagsi R. Progress and controversies: radiation therapy for invasive breast cancer. CA Cancer J Clin 2014; 64: 135-152.

11. Tang L, Wei F, Wu Y, et al. Role of metabolism in cancer cell radioresistance and radiosensitization methods. J Exp Clin Cancer Res 2018; 37: 87.

12. Cosaceanu D, Budiu RA, Carapancea M, Castro J, Lewensohn R, Dricu A. Ionizing radiation activates IGF-1R triggering a cytoprotective signaling by interfering with Ku-DNA binding and by modulating Ku86 expression via a p38 kinase-dependent mechanism. Oncogene 2007; 26: 2423-2434.

13. Qiu GH. Protection of the genome and central protein-coding sequences by non-coding DNA against DNA damage from radiation. Mutat Res Rev Mutat Res 2015; 764: 108-117.

14. Tezuka M, Watanabe H, Nakamura S, et al. Antiapoptotic activity is dispensable for insulinlike growth factor I receptor-mediated clonogenic radioresistance after gamma-irradiation. Clin Cancer Res 2001; 7: 3206-3214.

15. Bartucci M, Morelli C, Mauro L, Ando S, Surmacz E. Differential insulin-like growth factor I receptor signaling and function in estrogen receptor (ER)-positive MCF-7 and ER-negative MDA-MB-231 breast cancer cells. Cancer Res 2001; 61: 6747-6754

16. Li L, Qi X, Williams M, Shi Y, Keegan AD. Overexpression of insulin receptor substrate-1, but not insulin receptor substrate- 2 , protects a $T$ cell hybridoma from activation-induced cell death. J Immunol 2002; 168: 6215-6223.

17. Lloret M, Lara PC, Bordon E, et al. IGF-1R expression in localized cervical carcinoma patients treated by radiochemotherapy. Gynecol Oncol 2007; 106: 8-11.

18. Turner BC, Haffty BG, Narayanan L, et al. Insulin-like growth factor-I receptor overexpression mediates cellular radioresistance and local breast cancer recurrence after lumpectomy and radiation. Cancer Res 1997; 57: 3079-3083.

19. Gupta K, Burns TC. Radiation-Induced Alterations in the Recurrent Glioblastoma Microenvironment: Therapeutic Implications. Front Oncol 2018; 8: 503.

20. Osuka S, Sampetrean O, Shimizu T, et al. IGF1 receptor signaling regulates adaptive radioprotection in glioma stem cells. Stem Cells 2013; 31: 627-640. 
21. Pollak M. Insulin and insulin-like growth factor signalling in neoplasia. Nat Rev Cancer 2008; 8: 915-928.

22. Li D, Chi G, Chen Z, Jin X. MicroRNA-1225-5p behaves as a tumor suppressor in human glioblastoma via targeting of IRS1. Onco Targets Ther. 2018; Sep 28; 11: 6339-6350.

23. Valenciano A, Henriquez-Hernandez LA, Moreno M, Lloret M, Lara PC. Role of IGF-1 receptor in radiation response. Transl Oncol 2012; 5: 1-9.

24. Kelley K, Knisely J, Symons M, Ruggieri R. Radioresistance of Brain Tumors. Cancers (Basel) 2016; 8(4).

25. Trojanek J, Ho T, Del Valle L, et al. Role of the insulin-like growth factor $\mathrm{I}$ /insulin receptor substrate 1 axis in Rad51 trafficking and DNA repair by homologous recombination. Mol Cell Biol 2003; 23: 7510-7524.

26. Mardilovich K, Pankratz SL, Shaw LM. Expression and function of the insulin receptor substrate proteins in cancer. Cell Commun Signal 2009; 7: 14.

27. de Sousa MML, Bjoras KO, Hanssen-Bauer A, Solvang-Garten K, Otterlei M. p38 MAPK signaling and phosphorylations in the BRCT1 domain regulate XRCC1 recruitment to sites of DNA damage. Sci Rep 2017; 7: 6322.
28. Guo F, Li J, Du W, et al. mTOR regulates DNA damage response through NF-kappaB-mediated FANCD2 pathway in hematopoietic cells. Leukemia 2013; 27: 2040-2046.

29. Jang NY, Kim DH, Cho BJ, et al. Radiosensitization with combined use of olaparib and PI-103 in triple-negative breast cancer. BMC Cancer 2015; 15: 89.

30. Shen C, Oswald D, Phelps D, et al. Regulation of FANCD2 by the mTOR pathway contributes to the resistance of cancer cells to DNA doublestrand breaks. Cancer Res 2013; 73: 3393-3401.

31. Fang J, Zhou SH, Fan J, Yan SX. Roles of glucose transporter-1 and the phosphatidylinositol 3kinase/protein kinase $\mathrm{B}$ pathway in cancer radioresistance (review). Mol Med Rep 2015; 11: 1573-1581.

32. De Schutter H, Landuyt W, Verbeken E, Goethals L, Hermans R, Nuyts S. The prognostic value of the hypoxia markers CA IX and GLUT 1 and the cytokines VEGF and IL 6 in head and neck squamous cell carcinoma treated by radiotherapy +/- chemotherapy. BMC Cancer 2005; 5: 42.

33. Kunkel M, Moergel M, Stockinger M, et al. Overexpression of GLUT-1 is associated with resistance to radiotherapy and adverse prognosis in squamous cell carcinoma of the oral cavity. Oral Oncol 2007; 43: 796-803. 